fact that they have disturbed behaviour whether or not they have been abused makes diagnosis even more difficult. The point I wish to make is that special care should be taken when assessing the significance of the behaviour pattern in people with impairments of social interaction and communication.

LORNA WING

National Autistic Society,

London NW2 5RB

1 McCormack B. Sexual abuse and learning disabilities. B.MI 1991;303:143-4. (20 July.

SIR, - Dr Andrew J Wiener,' in commenting on my editorial on the long term effects of child sexual abuse, ${ }^{2}$ first constructs a straw man of his own making by claiming that my argument against child sexual abuse depends entirely on its propensity to inflict long term harm, then demolishes this thesis to his own satisfaction.

I agree that child sexual abuse is an evil irrespective of its long term consequences. In condemning a social evil there is no need to medicalise it by claiming that it causes illness. On the other hand, some social ills - for example, unemployment probably do contribute to morbidity and mortality and surely it is permissible to point this out.

Dr Wiener rightly raises the possibility that the same social and family factors that predict adult psychopathology may also predict vulnerability to sexual abuse. We are preparing for publication data showing that the sexual abuse itself contributes to adult psychopathology independently of the disrupted and deprived background which enhances the risks of being abused.

The law on sexual contact with children could be changed tomorrow and some moral convulsion could conceivably alter the public's attitude to the sexual use of children, but such contact would almost certainly go on producing immediate and long term psychological and emotional damage to those children. Child sexual abuse is in my opinion a medical problem as well as a moral and legal problem, and the clear recognition of this, far from "stunting" our view of the rights of children, as asserted by Dr Wiener, provides information essential for their protection.

PAUL MULLEN

Department of Psychological Medicine,

University of Otago.

Dunedin,

New Zealand

1 Wiener AJ. Consequences of child sexual abuse. BMF 1991;303: 415. (17 August.)

2 Mullen PE. The consequences of child sexual abuse. BMF 1991;303:144-5. (20 July.)

\section{Availability of cadaver organs for transplantation}

SIR,-In discussing the availability of cadaver organs for transplantation Dr David J Hill and colleagues question whether current clinical criteria are sufficiently exhaustive to ensure that all brain stem function has permanently ceased.' They further claim that in North America theatre staff are concerned that ventilated, beating heart donors are not truly dead when operations to remove organs begin and that the same anxieties exist in the United Kingdom, including among anaesthetists. In support of this contention they quote our review of the management of multiple organ donors as stating that anaesthetists both anaesthetise and paralyse brain stem dead donors. This is misleading. Hypertension and tachycardia are not unusual during organ retrieval, and because of the importance of maintaining haemodynamic stability at this time, we suggested that glyceryl trinitrate, nitroprusside, or isoflurane (a volatile anaesthetic agent that is a potent vasodilator) could be used if necessary to control these responses. ${ }^{2}$

Explanations for these haemodynamic changes have included intact spinal reflex arcs between afferent pain fibres and sympathetic efferent nerves, humoral responses after adrenal stimulation, and residual brain stem function. ${ }^{3}$ Although apparently some anaesthetists are more comfort able if volatile anaesthetic agents are administered during organ retrieval, the vast majority consider that the use of such agents other than to control potentially harmful tachycardia and hypertension is illogical for brain stem dead donors. ${ }^{4}$ It is also recommended that somatic motor reflexes, similarly mediated at a spinal level, should be controlled with a muscle relaxant simply to facilitate surgery.

The presence of these reflex haemodynamic and motor responses to surgical stimulation and the need to control them during organ retrieval do not in our view invalidate the current clinical criteria for diagnosing irreversible damage to the brain stem and thereby establishing that there is no prospect of the patient recovering.

A C TIMMINS

C J HINDS

Anaesthetic Laboratory,

St Bartholomew's Hosp
London EC1A 7BE

1 Hill DJ, Evans DW, Gresham GA. Availability of cadaver organs for transplantation. BMJ 1991:303:312. (3 August.)

2 Timmins AC, Hinds CJ. Management of the multiple-organ donor. Current Opinion in Anaesthesiology 1991;4:287-92.

3 Wetzel RC, Setzer N, Stiff JL, Roberts MC. Hemodynam responses in brain dead organ donor patients. Anesth Anal 1985;64:125-8.

4 Bodenham A, Park GR. Care of the multiple organ donor. Intensive Care Med 1989;15:340-8.

\section{Antepartum haemorrhage and cervical cancer}

SIR, - I was interested in the comment from the National Maternity Hospital consultants about bleeding in pregnancy among women with carcinoma of the cervix.' The experience of clinical colleagues must always be respected when discussing clinical matters, but so often a small figure variation may be misleading when unusual conditions are being considered.

$\mathrm{Mr}$ John $\mathrm{M}$ Stronge and colleagues quote their experiences of four women with carcinoma of the cervix presenting in pregnancy at $40,34,32$, and 36 weeks of gestation. All had "substantial haemorrhage." They do not quote any women with carcinoma of the cervix in this time who presented with lesser bleeding. This is against my clinical experience. While preparing the $\mathrm{ABC}$ series I searched my memory and could think of eight to 10 women with invasive carcinoma of the cervix in pregnancy, of whom two had moderate bleeding the rest had considerably less, some having no real bleeding at all but only spotting.

When such small series are examined we must turn to published reports; these confirm that many women with invasive carcinoma of the cervix discovered in pregnancy have little bleeding. Many cases, even of invasive cancer, are diagnosed from cytological screening and subsequent colposcopy of women with an abnormal smear; these women do not bleed much and so would weight the figures.

In a series collected by Moore and Gusberg of 22 women with invasive carcinoma of the cervix in pregnancy "most had no symptoms"; two had contact bleeding and three had "some bleeding." Hence less than $20 \%$ of their series could have been scored as having substantial bleeding.

Cromer and Hawkin reviewed 20 women with carcinoma of the cervix in pregnancy; four of these had carcinoma in situ and 16 invasive carcinoma.
Seven of those with invasive carcinoma had some bleeding but only one $(6 \%)$ had severe bleeding.

A bigger series was collected by Hacker et al, who summarised the findings from other sources and ended with 263 women with invasive carcinoma of the cervix out of 579795 pregnancies. Of these cancers 168 were diagnosed either in the firs trimester or in the postpartum period and are not relevant to this discussion. In the remainder, $35 \%$ of the women presented with a discharge or no symptoms and $65 \%$ had some bleeding. But the range of the duration of the symptom was $2 \cdot 5-6 \cdot 1$ months (mean 4.5 months) - the bleeding could not have been substantial or someone would have taken some action.

In 1906 Bernard Shaw (born as a breech presentation as a district case in The National Hospital) presented Doctor's Dilemma to the world in London.' In the preface to that book he states, "Even trained statisticians often fail to appreciate the extent to which statistics are vitiated by the unrecorded assumptions of their interpreters."

GEOFFREY CHAMBERL.AIN

St George's Hospital Medical School,

London SW 17 ORE

1 Stronge JM, Boyd W, Rasmussen MJ. Antepartum haemorrhag and cervical cancer. BMJ 1991;303:249-50. (27 July.)

2 Moore D, Gusberg S. Cancer precursors in pregnancy. Obste Gynecol 1959;13:530-8.

3 Cromer J, Hawkin S. Cancer of the cervix and pregnancy. Obste Gynecol 1963;22:346-51.

4 Hacker NF, Berek JS, Lagasse LD, Charles EH, Savage EW, Moore JG. Carcinoma of the cervix associated with pregnancy. Obstet Gynecol 1982;59:735-46.

5 Shaw B. The doctor's dilemma. London: Penguin, 1946:61.

\section{Breast carcinomas diagnosed in the 1980s}

SIR,-Drs H Joensuu and S Toikkanen compared breast carcinomas diagnosed in the 1980s with those diagnosed in earlier decades.' The histological factors compared in the study included a measurement of the mitotic count and an assessment of the overall tumour grade.

We have recently shown that a delay in fixation of six hours produces a reduction of about $50 \%$ in the number of observable mitotic figures in breast carcinomas. ${ }^{23}$ In some tumours the decreased mitotic count can result in change in the overall Bloom and Richardson tumour grade and hence prognostic group. ${ }^{3}$ We believe that it is now essential to include details of tissue fixation in any study comparing breast carcinomas on the basis of mitotic counts, particularly if tumour grade and subsequent prognosis are to be discussed.

R D START S S CROSS J H F SMITH

Department of Histopathology,

Northern General Hospital,

Sheffield S5 7AU

1 Joensuu H, Toikkanen S. Comparison of breast carcinoma diagnosed in the 1980s with those diagnosed in the 1940s to

2 Start RD, Flynn MS, Rogers K, Smith JHF. Delayed fixation significantly decreases observed mitotic figures in breas carcinoma. F Pathol 1991;163:154A.

3 Start RD, Flynn MS, Cross SS, Rogers K, Smith JHF. Is the grading of breast carcinoma affected by a delay in fixation? Virchows Arch [A] (in press).

\section{Mental health needs of Asians}

SIR,-Dr Tony Dixon reported the results of a survey, conducted by the Confederation of Indian Organisations, of Asians living in Haringey.

I have analysed preliminary findings of a follow up study of a cohort of first generation immigrants from the Indian subcontinent, all of whom were 